\title{
Treatment of adult ADHD: Is current knowledge useful to clinicians?
}

\author{
Terje Torgersen ${ }^{1,2}$ \\ Bjørn Gjervan ${ }^{1,3}$ \\ Kirsten Rasmussen ${ }^{3}$ \\ 'Department of Psychiatry, \\ Sykehuset Levanger, Helse \\ Nord-Troendelag HF, Levanger, \\ Norway; ${ }^{2}$ Faculty of Medicine \\ and ${ }^{3}$ Department of Psychology, \\ Norwegian University of Science \\ and Technology, Trondheim, Norway
}

Correspondence:Terje Torgersen Department of Psychiatry, Sykehuset Levanger, Helse Nord-Troendelag HF, 7600 Levanger, Norway

Email terje.torgersen@ntny.no

\begin{abstract}
Psychostimulant drugs have for decades been considered the cornerstone of ADHD treatment. Non-stimulant drugs have also been reported successful. However, many controlled studies exclude patients with comorbidities typical for patients seen in clinical setting. Many patients are also considered non-responders to medication. Current knowledge might not be directly useful to clinicians. The present article reviews the literature on pharmacological and psychotherapeutic treatment in adult ADHD emphasizing comorbidity and other clinically important factors, as well as ADHD specific outcomes. Thirty-three relevant studies of pharmacotherapy and three studies of psychotherapy were included. Most subjects had little current comorbidity, but some studies included subjects with substance use disorder. Significant effect of treatment on ADHD symptoms was found in most studies using pharmacotherapy and all studies of psychotherapy. Both positive and negative effects on comorbid anxiety and depression measures were reported. Pharmacotherapy did not seem to have effect on substance use disorder. Few pharmacotherapy studies conducted any long-term follow-up; two studies that did, found that most subjects had discontinued medication. A clear-cut dose-respons relationship was not substanciated. In conclusion, clinicians have good support for both pharmacological and psychotherapeutic treatment of ADHD in adults, but should take additional measures to deal with comorbidities as well as treatment adherence.
\end{abstract}

Keywords: ADHD, adults, treatment, stimulants, psychotherapy, comorbidity

\section{Introduction}

Attention-deficit/hyperactivity disorder (ADHD) has for a long time been recognized in children. During the last couple of decades, evidence has confirmed that the disorder persists into adulthood. The validity of the diagnosis is now recognized (Clarke et al 2005; Kooij et al 2005) although the prevalence of the disorder and the degree of sustained symptoms as well as the presentation of symptoms in adults are disputed.

As much of the research concerning ADHD has been conducted in America, the DSM-IV criteria (American Psychiatric Association 1994) have been widely used, while Europeans usually adhere to the ICD-10 criteria (World Health Organization 1992). Subtle differences between these two sets of criteria could be one of the reasons for differences in prevalence, and it is usually held that DSM-IV criteria identify higher prevalence than ICD-10 criteria (Tripp et al 1999; Foreman et al 2001).

The possibility of a reduction of symptoms and problems over time in ADHD patients has been a matter of concern. A central issue in this debate is the difference between syndromatic versus symptomatic persistence. A recent meta-analysis (Faraone et al 2006) suggested a higher rate of persistence if the subjects were defined as "ADHD in partial remission" versus "persistent ADHD". Most follow up studies, however, concern young adults with few subjects up to 30 years. In addition, surprisingly few follow up studies report on the treatment received by the subjects.

Adding to the complex questions about syndromatic or symptomatic persistence is the fact that comorbidity between ADHD and other psychiatric disorders is very 
common. Studies suggest that up to $90 \%$ (Nutt et al 2007) of adult patients with ADHD have one or more comorbid psychiatric disorder. The most common comorbid disorders in adults are anxiety disorders, affective disorders, substance abuse and antisocial personality disorder. Developmental disorders like autism spectrum disorders, Tourette and tic disorders, developmental delay and learning disorders have also frequently been reported as comorbid to ADHD. In addition they are important differential diagnoses. The high prevalence of comorbidity complicates the diagnostic process as well as treatment and some studies indicate that high rates of comorbidity in adult ADHD contribute negatively to the treatment outcome (Jensen et al 1997). A diagnosis of ADHD has been associated with functional impairment in important life aspects like education, work and relationships (Murphy and Barkley 1996; Torgersen et al 2006). Persistent ADHD in adults is also common among prison inmates (Rasmussen et al 2001), and teens and adults with ADHD have an increased frequency of vehicular accidents and other driving-related impairments (Barkley et al 2005).

Psychostimulant drugs have for decades been considered the cornerstone of ADHD treatment. Many clinicians working with ADHD in children, adolescents or adults, have experienced impressing effects in some patients, both on symptoms and functional impairment. The research literature reports good short-term efficacy with stimulant drugs like methylphenidate and amphetamine for ADHD-symptoms in children, adolescents (Smith et al 2000; Schachter et al 2001) and adults (Faraone et al 2004), and there is some evidence for long-term efficacy in children (Wilens et al 2002; MTA Cooperative Group 2004). Efficacy for other pharmacological agents like atomoxetine, tricyclic antidepressants, bupropion and antihypertensives, has also been reported (Wilens et al 2002).

In spite of effective psychopharmacological treatment of core ADHD symptoms, there is evidence for residual symptoms and long lasting functional impairment in many adult patients. Research indicates that $20 \%-50 \%$ of adults are considered non-responders to stimulants due to insufficient symptom reduction or inability to tolerate adverse effects (Wender 1998; Wilens et al 2002). Adult responders often show a reduction in $50 \%$ or less of the core ADHD symptoms (Safren et al 2005). Furthermore, the correlation between symptoms and impairment has been reported to be low; symptoms predicting less than $25 \%$ of the variance in impairment (Gordon et al 2006). Weiss and colleagues argue that we need more research on effectiveness variables like comorbidity, functional impairment, substance abuse and compliance or treatment adherence (Weiss et al 2006), to evaluate the true clinical impact of the results from shortterm psychopharmacological trials. The importance of this is further emphasized by the likelihood of an increased number of adult patients with ADHD in psychiatry due to increased recognition and awareness (Asherson et al 2007).

The present article reviews the literature on pharmacological and psychotherapeutic treatment in adult ADHD with emphasis on comorbidity as well as ADHD-specific outcome measures. Furthermore, the authors will evaluate the effect of treatment on other clinically important outcome measures, like depression, anxiety, quality of life and long-term treatment adherence or compliance.

\section{Method}

\section{Search strategy}

We searched for relevant studies on the most commonly used and extensively studied stimulants and non-stimulants, and psychotherapy, in adult ADHD, in the following electronic databases: Pubmed, EMBASE, PsycINFO and the Cochrane database until January 2007. Citations from identified articles were also searched for relevant studies.

\section{Inclusion criteria}

We used the following criteria for considering papers to this review:

1. All relevant randomized controlled trials.

2. Adults ( $>18$ years) diagnosed with ADHD criteria according to DSM-IV (American Psychiatric Association 1994) and ICD-10 (World Health Organization 1992). Some studies applying older versions of the two diagnostic systems were also included.

3. Treatment with methylphenidate, dexamphetamine/ amphetamine, atomoxetine, bupropion and imipramine administered at any dosage as part of any treatment regimen, and psychotherapy of all kinds.

4. Placebo/non-intervention control group.

5. The outcome measures should be clinically important, like ADHD symptoms and other features of mental health. Trials mainly focusing on variables like driving performance, nevrocognitive and neuroimaging effects, were not considered in this review.

\section{Results}

Thirty-six studies met our criteria for inclusion in this review; 33 studies of pharmacotherapy and only 3 studies of psychotherapy. A large variety of outcome measures was applied. All studies used some kind of ADHD symptom 
rating scale, and some used more than one type of ADHD symptom scale or measure. Rating scales that are not ADHD symptom specific, like Hamilton anxiety and depression scales (HAM-A/D) and Beck depression and anxiety inventories (BDI/BAI), were frequently used. The physician rated Clinical Global Impression (CGI) was the most frequently used outcome measure.

There were relatively small numbers of drop-out in most of the pharmacological studies. Adverse effects were reported to be negligible in all studies.

\section{Pharmacotherapy: methylphenidate}

The literature search revealed 18 relevant randomized, placebo-controlled trials with methylphenidate in adults with ADHD, including one study with dexmethylphenidate (Wood et al 1976; Mattes et al 1984; Gualtieri et al 1985; Wender et al 1985; Spencer et al 1995, 2005, 2006; Kuperman et al 2001; Levin et al 2001, 2006, 2007; Schubiner et al 2002; Tenenbaum et al 2002; Bouffard et al 2003; Kooij et al 2004; Carpentier et al 2005; Biederman et al 2006; Reimherr et al 2007). Study design features and outcome measures are presented in Table 1. Except from two studies from the Netherlands (Kooij et al 2004; Carpentier et al 2005) and one from Canada (Bouffard et al 2003) all studies are performed in the US. The number of participants in the studies varied between 8 and 221, and the total number of patients was 991 (372 females and 619 males; F/M-ratio 0.60). The age ranged between 17 and 60 years, and mean age in the samples ranged between 27.5 and 42 years.

A majority of the studies had duration of 3-7 weeks, while three studies lasted 12-14 weeks. Two studies reported follow-up data after 3-6 (Gualtieri et al 1985) and 6-12 months (Mattes et al 1984), respectively. These two studies found that almost none of the patients still used methylphenidate at the time of follow-up. The dose of methylphenidate varied from a mean dose of $0.2 \mathrm{mg} / \mathrm{kg} /$ day to $1.1 \mathrm{mg} / \mathrm{kg} /$ day. Seven studies were using a high-dose ( $>0.9 \mathrm{mg} / \mathrm{kg} /$ day $)$.

We ranked current comorbidity into low, moderate, and high according to the following criteria: The study was ranked as low in current comorbidity if there was no or very sparse information on comorbidity, only lifetime comorbidity presented, or low numbers of current comorbid disorders like anxiety and mood disorders only. The study was ranked as moderate in current comorbidity if the sample had more than $25 \%$ current comorbid major depression, substance abuse or alcohol abuse, and/or personality disorders. Studies presenting more than $75 \%$ current comorbid major depression, substance abuse or alcohol abuse, and/or personality disorders were ranked as high in comorbidity. Eleven studies were ranked as having low rates of comorbidity, including eight studies with no or very sparse information on current comorbidity. Three studies were ranked as having moderate current comorbidity, showing a substantial number of patients with current personality disorders, substance abuse/alcohol abuse or affective disorders. Four studies with $100 \%$ current comorbid substance abuse disorder were ranked as high in comorbidity.

Five of the seven studies using high dose methylphenidate found significant ADHD symptom relief in favor of active drug. One study with a small sample size and one large study with high comorbidity found no significant differences. Five out of 10 studies using small/moderate doses $(<0.9 \mathrm{mg} / \mathrm{kg} /$ day $)$ found no significant effects of methylphenidate, while the other five found significant effect. One study using fixed doses of 20,30 or $60 \mathrm{mg} /$ day of dexmethylphenidate-extended release (Spencer et al 2006) found significant effect of active drug compared to placebo, but did not find a significant dose-response relationship, even if the highest dose numerically had the highest response. Reimherr and colleagues (2007) divided the sample into responders and non-responders to methylphenidate, and found that the responders ended up with a significant lower dose than non-responders, $57 \mathrm{mg}$ /day versus $75 \mathrm{mg} /$ day, respectively.

The placebo responses observed in the latest and largest studies are considerably higher than in earlier studies. These large placebo responses are shown both in studies with low comorbidity, and studies with high levels of comorbidity.

One out of four studies with 100\% current comorbid substance abuse disorder found initial efficacy for methylphenidate (Schubiner et al 2002). However, at the end of trial the differences in response rates between drug and placebo became nearly identical (methylphenidate $50 \%$ versus placebo $56 \%$ at week 12). Reduction in ADHD symptoms measured by an 18-item self-report scale did not produce significant differences between methylphenidate and placebo at any point in the study. One out of these four studies found a tendency towards positive effect on the substance abuse. In all these studies the patients received additional cognitive behavioral therapy.

A significant positive effect of methylphenidate treatment for comorbid symptoms of anxiety was reported in only one study (Bouffard et al 2003), while another study showed a statistically significant negative effect on outcome measures of depression and anxiety (Kooij et al 2004). One study 
Table I Sample and study design features, and ADHD symptom specific outcome measures, of I8 double-blind, placebo controlled studies on methylphenidate (MPH) in adult ADHD

\begin{tabular}{|c|c|c|c|c|c|c|c|c|}
\hline Authors & $\mathbf{N}$ & $\begin{array}{l}\text { Rank of current } \\
\text { comorbidity }^{a}\end{array}$ & $\begin{array}{l}\text { Length } \\
\text { of study }\end{array}$ & $\begin{array}{l}\text { Dose } \\
\left(\mathrm{mg} / \mathrm{kg} / \mathrm{day}^{\mathrm{b}}\right) \\
\text { and type } \\
\text { of MPH }\end{array}$ & $\begin{array}{l}\text { Efficacy } \\
\text { rated } r e\end{array}$ & $\begin{array}{l}\text { hysician } \\
\text { onse }^{c}\end{array}$ & $\begin{array}{l}\text { Efficac } \\
\text { rated } r\end{array}$ & \\
\hline Biederman & 141 & Low & 6 weeks & 0.99 & $\mathrm{MPH}$ & $66 \%$ & & \\
\hline 2006 & & & & OROS & Placebo & $39 \%$ & & \\
\hline $\begin{array}{l}\text { Bouffard } \\
2003\end{array}$ & 30 & Low & 5 weeks & $\begin{array}{l}0.4-0.6 \\
\mathbb{I R}\end{array}$ & & & $\begin{array}{l}\text { MPH sig } \\
\text { than Pla }\end{array}$ & better \\
\hline $\begin{array}{l}\text { Carpentier } \\
2005\end{array}$ & 25 & High & 8 weeks & $\begin{array}{l}0.2-0.4-0.6 \\
I R\end{array}$ & $\begin{array}{l}\text { MPH } \\
\text { Placebo } \\
\text { Not sign }\end{array}$ & $\begin{array}{l}36 \% \\
20 \%\end{array}$ & & \\
\hline $\begin{array}{l}\text { Gualtieri } \\
1985\end{array}$ & 8 & Low & 5 days & $\begin{array}{l}0.6 \\
I R\end{array}$ & & & No sign & $\mathrm{MPH}$ \\
\hline $\begin{array}{l}\text { Kooij } \\
2004\end{array}$ & 45 & Moderate & 7 weeks & $\begin{array}{l}0.9 \\
\mathbb{I R}\end{array}$ & $\begin{array}{l}\text { MPH } \\
\text { Placebo }\end{array}$ & $\begin{array}{l}51 \% \\
18 \%\end{array}$ & $\begin{array}{l}\text { MPH } \\
\text { Placebo }\end{array}$ & $\begin{array}{l}42 \% \\
13 \%\end{array}$ \\
\hline $\begin{array}{l}\text { Kuperman } \\
2001\end{array}$ & 17 & Low & 7 weeks & $\begin{array}{l}0.9 \\
\mathbb{I R}\end{array}$ & $\begin{array}{l}\text { MPH } \\
\text { Placebo } \\
\text { Not sign }\end{array}$ & $\begin{array}{l}50 \% \\
27 \%\end{array}$ & No sign & $\mathrm{MPH}$ \\
\hline $\begin{array}{l}\text { Levin ed } \\
2001\end{array}$ & 10 & Low & 4 weeks & $\begin{array}{l}0.26 \\
\text { Slow-Release }\end{array}$ & $\begin{array}{l}\text { No sign. } \\
\text { effect }\end{array}$ & & No sign & $\mathrm{MPH}$ \\
\hline $\begin{array}{l}\text { Levin fr } \\
2006 \mathrm{a}\end{array}$ & 65 & High & 12 weeks & $\begin{array}{l}\text { Max. I, I } \\
\text { Sustained- } \\
\text { Release }\end{array}$ & $\begin{array}{l}\text { MPH } \\
\text { Placebo } \\
\text { Not sign }\end{array}$ & $\begin{array}{l}19 \% \\
39 \%\end{array}$ & $\begin{array}{l}\text { MPH } \\
\text { Placebo } \\
\text { Not sig. }\end{array}$ & $\begin{array}{l}34 \% \\
46 \%\end{array}$ \\
\hline $\begin{array}{l}\text { Levin fr } \\
\text { 2006b }\end{array}$ & 106 & High & 14 weeks & $\begin{array}{l}0.78 \\
\text { Slow-Release }\end{array}$ & $\begin{array}{l}\text { MPH } \\
\text { Placebo } \\
\text { Not sign }\end{array}$ & $\begin{array}{l}34 \% \\
30 \%\end{array}$ & $\begin{array}{l}\text { MPH } \\
\text { Placebo } \\
\text { Not sigr }\end{array}$ & $\begin{array}{l}47 \% \\
55 \%\end{array}$ \\
\hline $\begin{array}{l}\text { Mattes } \\
1984\end{array}$ & 26 & Moderate & 6 weeks & $\begin{array}{l}0.7 \\
\mathrm{IR}\end{array}$ & No sign. & & No sign & \\
\hline $\begin{array}{l}\text { Reimherr } \\
2007\end{array}$ & 41 & Low & 4 weeks & $\begin{array}{l}0.83-0.89 \\
\text { OROS }\end{array}$ & $\begin{array}{l}\text { MPH } \\
\text { Placebo }\end{array}$ & $\begin{array}{l}42 \% \\
13 \%\end{array}$ & $\begin{array}{l}\text { MPH } \\
\text { Placebo }\end{array}$ & $\begin{array}{l}41 \% \\
14 \%\end{array}$ \\
\hline $\begin{array}{l}\text { Schubiner } \\
2002\end{array}$ & 48 & High & 12 weeks & $\begin{array}{l}0.99 \\
\mathbb{I R}\end{array}$ & $\begin{array}{l}\text { MPH } \\
\text { Placebo }\end{array}$ & $\begin{array}{l}50 \% \\
56 \%\end{array}$ & No sign & \\
\hline Spencer & 23 & Low & 7 weeks & 1.0 & $\mathrm{MPH}$ & $78 \%$ & & \\
\hline 1995 & & & & IR & Placebo & $4 \%$ & & \\
\hline Spencer & 146 & Low & 6 weeks & I.I & $\mathrm{MPH}$ & $68 \%$ & & \\
\hline 2005 & & & & IR & Placebo & $17 \%$ & & \\
\hline Spencer & 221 & Low & 5 weeks & $0.28-0.4 I-0.55$ & $\mathrm{MPH}$ & $53-61 \%$ & & \\
\hline 2006 & & & & d-MPH-ER & Placebo & $34 \%$ & & \\
\hline $\begin{array}{l}\text { Teenenbaum } \\
2002\end{array}$ & 24 & Low & 3 weeks & $\begin{array}{l}0.64 \\
\mathrm{IR}\end{array}$ & & & No sign & $\mathrm{MPH}$ \\
\hline $\begin{array}{l}\text { Wender } \\
1976\end{array}$ & 37 & Low & 5 weeks & $\begin{array}{l}0.6 \\
\text { IR }\end{array}$ & $\begin{array}{l}\text { MPH } \\
\text { Placebo }\end{array}$ & $\begin{array}{l}57 \% \\
11 \%\end{array}$ & $\begin{array}{l}\text { MPH sig } \\
\text { than Pla }\end{array}$ & better \\
\hline $\begin{array}{l}\text { Wood } \\
1976\end{array}$ & II & Moderate & 4 weeks & $\begin{array}{l}0.28-0.84 \\
\mathbb{I R}\end{array}$ & & & $\begin{array}{l}\text { Respons } \\
\text { out of I }\end{array}$ & -1 in 8 \\
\hline
\end{tabular}

Abbreviations: IR, immediate release; OROS, osmotic release oral system; d-MPH-ER, dexmethylphenidate-extended release.

${ }^{a}$ The study was ranked as low in current comorbidity if there was no or very sparse information on comorbidity, only lifetime comorbidity presented, or low numbers of comorbid disorders like anxiety and mood disorders only. The study was ranked as moderate in current comorbidity if the sample had more than $25 \%$ current comorbidity on major depression, substance abuse or alcohol abuse, and/or personality disorders. Studies presenting more than $75 \%$ current comorbidity on major depression, substance abuse or alcohol abuse, and/or personality disorders were ranked as high comorbidity.

bWhen dose is presented in $\mathrm{mg} /$ day, these numbers is recalculated to weight-normalized dose ( $\mathrm{mg} / \mathrm{kg} /$ day) using 50th percentile weight for age (Wilens, Spencer, and Biederman 189-202).

'When available the measures presented are response rates defined as percent of patients experiencing $>30 \%$ reduction of ADHD symptoms on an ADHD rating scale, and/or much or very much improved on Clinical Global Impression-Improvement (CGI-I). If this definition was not used, we present the response rates as defined by the paper. 
showed a negative effect size of -0.54 on anxiety as measured by BAI (Tenenbaum et al 2002).

One of the studies included an outcome measure on quality of life, the Quality of Life Enjoyment and Satisfaction Questionnaire (Q-LES-Q), but there was no effect of medication on this measure (Spencer et al 2006).

\section{Pharmacotherapy: amphetamines}

The literature search revealed six randomized, placebocontrolled trials with amphetamines in adults with ADHD (Paterson et al 1999; Taylor and Russo 2000; Spencer et al 2001; Taylor and Russo 2001; Weisler et al 2006; Weiss and Hechtman 2006). An overview of the studies is presented in Table 2. There was one study from Australia (Paterson et al 1999) and one from Canada (Weiss and Hechtman 2006); all other studies were from the US. The number of participants in the studies varied between 17 and 255, and the total number of patients was 464 (190 females and 274 males; F/M-ratio $0.69)$. The age ranged between 18 and 76 years, and mean age in the samples ranged between 35.5 and 41.2 years.
The treatment period ranged from 2 to 20 weeks. The dose of amphetamine varied between 10 and $60 \mathrm{mg} /$ day. Three studies gave exact information about current comorbidity, and in all of this comorbidity were considered to be low.

In all six studies the efficacy of amphetamine was superior to placebo. In the study by Spencer and colleagues (Spencer et al 2001) the percentage of subjects who improved, defined as a $30 \%$ reduction in the ADHD symptom rating scale, was very large compared to placebo (70\% vs $7 \%)$. In a study by Weisler and colleges comprising 255 patients (Weisler et al 2006) the efficacy of mixed amphetamine salts was also significant better than placebo, however, the number of responders was high for placebo too (34\%). The study could not document a significant dose-response effect.

None of the studies on amphetamines reported any effect on comorbid disorders or symptoms. In one large study of four weeks duration (Weisler et al 2006) the drop-out rate was $28 \%$, while in a study by Weiss and colleagues (Weiss and Hechtman 2006) of 20 weeks duration the drop-out rate in the treatment group was $40 \%$.

Table 2 Sample and study design features, and ADHD symptom specific outcome measures, of 6 double-blind, placebo controlled studies on amphetamines in adult ADHD

\begin{tabular}{|c|c|c|c|c|c|c|c|}
\hline Authors & $\mathbf{N}$ & $\begin{array}{l}\text { Rank of current } \\
\text { comorbidity }^{\mathrm{a}}\end{array}$ & $\begin{array}{l}\text { Length } \\
\text { of study }\end{array}$ & $\begin{array}{l}\text { Type of amphetamine } \\
\text { and mean dose } \\
(\mathrm{mg} / \text { day })\end{array}$ & $\begin{array}{l}\text { Efficacy; } p \\
\text { rated resp }\end{array}$ & $\begin{array}{l}\text { sician } \\
\text { nse }^{b}\end{array}$ & $\begin{array}{l}\text { Efficacy; patient } \\
\text { rated response }^{b}\end{array}$ \\
\hline Paterson 1999 & 45 & Low & 6 weeks & $\begin{array}{l}\text { Dexamphetamine } \\
20-25 \mathrm{mg} / \text { day }\end{array}$ & $\begin{array}{l}\text { Dexamph. } \\
\text { Placebo }\end{array}$ & $\begin{array}{r}58 \% \\
<10 \%\end{array}$ & $\begin{array}{l}\text { Dexamph. sign. } \\
\text { better than Placebo }\end{array}$ \\
\hline Spencer 200I & 27 & Low & 3 weeks & $\begin{array}{l}\text { Mixed amphetamine salts } \\
\text { (MAS) } \\
53.7 \mathrm{mg} / \text { day }\end{array}$ & $\begin{array}{l}\text { MAS } \\
\text { Placebo }\end{array}$ & $\begin{array}{r}70 \% \\
7 \%\end{array}$ & \\
\hline Taylor 200I & 17 & Low & 2 weeks & $\begin{array}{l}\text { Dexamphetamine } \\
10.2 \mathrm{mg} / \text { day }\end{array}$ & & & $\begin{array}{l}\text { Dexamph. sign. } \\
\text { better than Placebo }\end{array}$ \\
\hline Taylor 2000 & 22 & Low & 2 weeks & $\begin{array}{l}\text { Dexamphetamine } \\
21.8 \mathrm{mg} / \text { day }\end{array}$ & & & $\begin{array}{l}\text { Dexamph. } 48 \% \\
\text { Significantly better } \\
\text { than Placebo }\end{array}$ \\
\hline Weisler 2006 & 255 & Low & 4 weeks & $\begin{array}{l}\text { Mixed amphetamine salts } \\
\text {-extended release } \\
\text { (MAS-XR) } \\
\text { Fixed dose } \\
20 / 40 / 60 \mathrm{mg} / \text { day }\end{array}$ & $\begin{array}{l}\text { MAS-XR } \\
20 \mathrm{mg} \\
30 \mathrm{mg} \\
40 \mathrm{mg} \\
\text { Placebo } \\
\text { Effect size }\end{array}$ & $\begin{array}{r}58 \% \\
54 \% \\
61 \% \\
34 \% \\
0.8\end{array}$ & \\
\hline Weiss 2006 & 98 & Low & 20 weeks & $\begin{array}{l}\text { Dexamphetamine } \\
\text { max. } 40 \mathrm{mg} / \text { day }\end{array}$ & $\begin{array}{l}\text { Dexamph. } \\
\text { Placebo }\end{array}$ & $\begin{array}{l}64 \% \\
17 \%\end{array}$ & \\
\hline
\end{tabular}

aThe study was ranked as low in current comorbidity if there was no or very sparse information on comorbidity, only lifetime comorbidity presented, or low numbers of comorbid disorders like anxiety and mood disorders only. The study was ranked as moderate in current comorbidity if the sample had more than $25 \%$ current comorbidity on major depression, substance abuse or alcohol abuse, and/or personality disorders. Studies presenting more than $75 \%$ current comorbidity on major depression, substance abuse or alcohol abuse, and/or personality disorders were ranked as high comorbidity.

bWhen available the measures presented are response rates defined as percent of patients experiencing $>30 \%$ reduction of ADHD symptoms on an ADHD rating scale, and/or much or very much improved on Clinical Global Impression-Improvement (CGI-I). If this definition was not used, we present the response rates as defined by the paper, or effect size (computed by taking the mean outcome score of active treatment minus the mean outcome score of control/placebo and dividing the result by the pooled standard deviation). 


\section{Pharmacotherapy: nonstimulants}

Our literature search revealed eight randomized, placebocontrolled trials with non-stimulants in adults with ADHD meeting our inclusion criteria. The studies are presented in Table 3. Four of the studies used Bupropion in doses up to $400 \mathrm{mg}$ /day (Kuperman et al 2001; Wilens et al 2001, 2005; Adler et al 2006; Levin et al 2006), three studies used Atomoxetine/Tomoxetine in doses from $60-120 \mathrm{mg} /$ day (Spencer et al 1998; Michelson et al 2003), and one study used Desipramine with a mean dose of $147 \mathrm{mg} /$ day (Wilens et al 1996). The number of participants ranged from 21 to 280 , and the total number of patients was 888 (338 females and 550 males; F/M-ratio 0.61). Mean age in the samples ranged between 33 and 42 years. Except from one study with $100 \%$ comorbid substance abuse, we ranked all studies to be low in current comorbidity.

Good efficacy of the three different drugs was found, but only in short term trials. Out of four studies on bupropion, two studies found a moderate but robust effect (Wilens et al 2001, 2005). One study found no significant differences between active drug and placebo (Kuperman et al 2001). Neither did another study which included $100 \%$ comorbid substance abuse (Levin et al 2006).

We found only one study on desipramine, but this study had the largest differences in response rates between drug and placebo (68\% versus $0 \%$ ) among the eight studies. Two large studies of 10 weeks duration on atomoxetine did not present response rates, but presented low to moderate effect sizes $(0.35$ and 0.40$)$. Except from a small, 3 weeks study on tomoxetine, these studies provide the only evidence for the efficacy of atomoxetine in adult ADHD. One study on atomoxetine found a statistically negative effect on measures of depression (Michelson et al 2003).

\section{Psychotherapy}

The search revealed three randomized, controlled studies of psychotherapy in adult ADHD patients, two from Australia (Stevenson et al 2002, 2003) and one from the US (Safren et al 2005). The number of participants in the studies varied between 31 and 43, and the total number of patients was 109

Table 3 Sample and study design features, and ADHD symptom specific outcome measures, of 8 double-blind, placebo controlled studies on non-stimulants in adult ADHD

\begin{tabular}{|c|c|c|c|c|c|c|c|c|}
\hline \multirow{2}{*}{$\begin{array}{l}\text { Authors } \\
\text { Kuperman }\end{array}$} & \multirow{2}{*}{$\begin{array}{l}\mathbf{N} \\
\\
\\
22\end{array}$} & \multirow{2}{*}{$\begin{array}{l}\text { Rank of current } \\
\text { comorbidity } \\
\\
\text { Low }\end{array}$} & \multirow{2}{*}{$\begin{array}{l}\text { Length } \\
\text { of study } \\
7 \text { weeks }\end{array}$} & \multirow{2}{*}{$\begin{array}{l}\text { Type of drug } \\
\text { and mean } \\
\text { daily dose } \\
\text { Bupropion SR }\end{array}$} & \multicolumn{2}{|c|}{$\begin{array}{l}\text { Efficacy; physician } \\
\text { rated response }^{b}\end{array}$} & \multicolumn{2}{|c|}{$\begin{array}{l}\text { Efficacy; patient } \\
\text { rated response }^{b}\end{array}$} \\
\hline & & & & & Bupropion & $64 \%$ & No sign. dif & tween \\
\hline \multirow[t]{2}{*}{2001} & & & & Max. 300 mg/day & Placebo & $27 \%$ & Bupropion & Placebo \\
\hline & & & & & Not sign. & & & \\
\hline Levin & 65 & High & 12 weeks & Bupropion & Bupropion & $30 \%$ & Bupropion & $49 \%$ \\
\hline \multirow[t]{2}{*}{2006} & & & & Max. 400 mg/day & Placebo & $39 \%$ & Placebo & $46 \%$ \\
\hline & & & & & Not sign. & & Not sign. & \\
\hline Michaelson & 280 & Low & 10 weeks & Atomoxetine & Effect size & 0.35 & & \\
\hline $2003-1$ & & & & $60-120 \mathrm{mg} /$ day & & & & \\
\hline Michaelson & 256 & Low & 10 weeks & Atomoxetine & Effect size & 0.40 & & \\
\hline $2003-11$ & & & & $60-120 \mathrm{mg} /$ day & & & & \\
\hline Spencer & 21 & Low & 3 weeks & Tomoxetine & Tomoxetine & $52 \%$ & & \\
\hline 1998 & & & & 76 mg/day & Placebo & $9.5 \%$ & & \\
\hline Wilens & 41 & Low & 6 weeks & Desipramine & Desipramine & $68 \%$ & & \\
\hline 1996 & & & & 147 mg/day & Placebo & $0 \%$ & & \\
\hline Wilens & 40 & Low & 6 weeks & Bupropion SR & Bupropion & $52 \%$ & Bupropion & $76 \%$ \\
\hline 2001 & & & & $362 \mathrm{mg} / \mathrm{day}$ & Placebo & II\% & Placebo & $37 \%$ \\
\hline Wilens & 162 & Low & 8 weeks & Bupropion XL & Bupropion & $53 \%$ & Bupropion & \\
\hline \multirow[t]{2}{*}{2005} & & & & $393 \mathrm{mg} /$ day & Placebo & $31 \%$ & better than & \\
\hline & & & & & Effect size & 0.6 & & \\
\hline
\end{tabular}

${ }^{a}$ The study was ranked as low in current comorbidity if there was no or very sparse information on comorbidity, only lifetime comorbidity presented, or low numbers of comorbid disorders like anxiety and mood disorders only. The study was ranked as moderate in current comorbidity if the sample had more than $25 \%$ current comorbidity on major depression, substance abuse or alcohol abuse, and/or personality disorders. Studies presenting more than $75 \%$ current comorbidity on major depression, substance abuse or alcohol abuse, and/or personality disorders were ranked as high comorbidity.

${ }^{b}$ When available the measures presented are response rates defined as percent of patients experiencing $>30 \%$ reduction of ADHD symptoms on an ADHD rating scale, and/or much or very much improved on Clinical Global Impression-Improvement (CGI-I). If this definition was not used, we present the response rates as defined by the paper, or effect size (computed by taking the mean outcome score of active treatment minus the mean outcome score of control/placebo and dividing the result by the pooled standard deviation). 
(44 females and 65 males; F/M-ratio 0.68). Mean age of the samples ranged between 36 and 45.5 years.

The treatment period ranged from 8 to 15 weeks, and two studies had follow-up periods of 2 and 12 months, respectively (Stevenson et al 2002, 2003). All three studies included patients on medication, but only two controlled for the effect of medication. All three studies applied a form of cognitive behavior therapy (CBT), but the various interventions differed. An overview of the studies is presented in Table 4. None of the studies presented exact information on current comorbidity.

Safren and colleagues (2005) examined the efficacy of combining medical treatment and cognitive therapy. Compared to controls, combined treatment was found to be more effective than medical treatment alone. Post treatment ADHD symptom specific outcome measures showed 56\% responders in the combined treatment group versus $13 \%$ in the control group (medication only). This study also reported a significant positive effect of CBT on measures of anxiety and depression.

In two studies by Stevenson and colleagues (2002, 2003 ) the efficacy of cognitive therapy alone was examined.
Participants were either on medication or not and were randomly assigned to a treatment group or waiting list control. In both studies outcome measures showed improvement in ADHD symptoms. In one of the studies $36 \%$ of the patients had improved at the end of the treatment period (Stevenson et al 2002), and this increased to $50 \%$ at follow up after 12 months (effect size 1,4). In the other study (Stevenson et al 2003) 47\% had improved at the end of treatment, but this rate decreased to $36 \%$ at follow-up two months later.

Neither medication nor comorbidity seemed to have any major influence on treatment efficacy.

\section{Discussion}

Previous reviews (Wilens et al 2002; Dodson 2005) and a meta-analysis on pharmacologic treatment of adult ADHD (Faraone et al 2004) have shown robust efficacy of stimulants on the core symptoms of ADHD in adults, and a doseresponse relationship has been postulated. However, the lack of long term placebo controlled studies is emphasized by many authors, and in the present review we still could not find any randomized, controlled, long-term pharmacological treatment study of adult ADHD. There is robust evidence

Table 4 Sample and study design features, and ADHD symptom specific outcome measures, of 3 randomized, controlled studies of psychotherapy in adult ADHD

\begin{tabular}{|c|c|c|c|c|c|c|c|c|}
\hline \multirow{2}{*}{$\begin{array}{l}\text { Authors } \\
\text { Safren } 2005\end{array}$} & \multirow{2}{*}{$\begin{array}{l}\mathbf{N} \\
\\
31\end{array}$} & \multirow{2}{*}{$\begin{array}{l}\text { Rank of } \\
\text { current } \\
\text { comorbidity } \\
\text { Low }\end{array}$} & \multirow{2}{*}{$\begin{array}{l}\text { Length } \\
\text { of study } \\
15 \text { weeks }\end{array}$} & \multirow{2}{*}{$\begin{array}{l}\text { Type of } \\
\text { psychotherapy }\end{array}$} & \multicolumn{2}{|c|}{$\begin{array}{l}\text { Efficacy: physician } \\
\text { rated response }^{b}\end{array}$} & \multicolumn{2}{|c|}{$\begin{array}{l}\text { Efficacy: patient } \\
\text { rated response }\end{array}$} \\
\hline & & & & & Effect size & $1.2-1.4$ & Effect size & 1.7 \\
\hline & & & & Behavioural & & & & \\
\hline & & & & Therapy (CBT) & Responders: & & & \\
\hline & & & & + continued medication & CBT & $56 \%$ & & \\
\hline & & & & All patients on medication & Control & $13 \%$ & & \\
\hline \multirow[t]{6}{*}{ Stevenson 2002} & 43 & Low & 8 weeks & Cognitive & & & Responder & \\
\hline & & & +2 and & Remediation & & & Post treatm & $36 \%$ \\
\hline & & & 12 months & Programme (CRP) & & & 2 months & $55 \%$ \\
\hline & & & follow-up & $\begin{array}{l}+ \text { continued } \\
\text { medication }\end{array}$ & & & 12 months: & $50 \%$ \\
\hline & & & & Med. 22 & & & Effect size & 1.4 \\
\hline & & & & Not med. 21 & & & & \\
\hline \multirow[t]{5}{*}{ Stevenson 2003} & 35 & Low & 8 weeks & Psychosocial self- & & & Responder & \\
\hline & & & +2 months & directed intervention & & & Post treatm & $47 \%$ \\
\hline & & & follow-up & + continued medication & & & 2 months & $36 \%$ \\
\hline & & & & Med. 23 & & & & \\
\hline & & & & Not med. 12 & & & & \\
\hline
\end{tabular}

aThe study was ranked as low in current comorbidity if there was no or very sparse information on comorbidity, only lifetime comorbidity presented, or low numbers of comorbid disorders like anxiety and mood disorders only. The study was ranked as moderate in current comorbidity if the sample had more than $25 \%$ current comorbidity on major depression, substance abuse or alcohol abuse, and/or personality disorders. Studies presenting more than $75 \%$ current comorbidity on major depression, substance abuse or alcohol abuse, and/or personality disorders were ranked as high comorbidity.

bWhen available the measures presented are response rates defined as percent of patients experiencing $>30 \%$ reduction of ADHD symptoms on an ADHD rating scale, and/or much or very much improved on Clinical Global Impression-Improvement (CGI-I). If this definition was not used, we present the response rates as defined by the paper, or effect size (computed by taking the mean outcome score of active treatment minus the mean outcome score of control/placebo and dividing the result by the pooled standard deviation). 
for the efficacy of methylphenidate and amphetamines on reducing the core ADHD symptoms over the first weeks of treatment, and in this first phase the drop-out rates are low and there are few problems with adverse effects. The same patterns are apparent for the non-stimulants bupropion, atomoxetine and desipramine, but the evidence is weaker due to fewer studies and lower response rates and effect sizes. Only low to moderate effect sizes $(0.35-0.40)$ were found in studies of atomoxetine.

Faraone and colleagues (2004) found in their metaanalysis of efficacy of methylphenidate in adult ADHD that larger effect sizes was associated with physician ratings of outcome and use of higher doses. The present authors also found that the use of physician based ratings of outcome still is dominating in pharmacological trials of adult ADHD. This may lead to an overestimation of efficacy possibly due to the physician being able to guess treatment assignment, as discussed by Schubiner and colleagues (2002).

Findings in our study indicate that the previous postulated dose-response relationship in stimulant treatment, in favor if high doses, is not so obvious. The dose-response relationship seems to be highly variable among patients, indicating that the dose must always be individualized for optimal efficacy and tolerability.

Two of the studies of methylphenidate conducted an open long-term follow up and found that very few patients continued medication at the time of follow up (Mattes et al 1984; Gualtieri et al 1985). These findings are in accordance with recent studies on compliance or treatment adherence. One recent report from Canada showed that compliance by the 7 th month after initial prescription was only $23.5 \%$ for methylphenidate modified release and $22.9 \%$ for mixed amphetamine salts extended release (Capone and McDonnel 2006). Evidence from pharmacy claim records also shows that adherence to prescriptions for ADHD treatment may be low (Perwien et al 2004). A report to Norwegian Health authorities on all adult ADHD patients treated with stimulant drugs in Norway in the period 1997-2003 (1328 patients), show that after two years only $20 \%$ were still in treatment, in spite of initial reports of good effect for most patients (Aanonsen et al 2004). Two long-term, open studies on mixed amphetamine salts extended release (24 months) and atomoxetine (97 weeks), showed rates of treatment adherence at end of study at $34 \%$ and 32.6\%, respectively (Adler et al 2005; Biederman et al 2005). Therefore, the evidence so far indicates that most adult ADHD patients choose to discontinue medication after some months, despite an apparently initial good response on core ADHD symptoms.
Most studies, both of medication and psychotherapy, had low rates of current comorbidity or were lacking exact information on this issue. We are therefore still lacking clinically important knowledge about the impact of comorbidity on response to treatment in adult ADHD. Still, the data on methylphenidate indicate that there is no or very little effect of stimulants in the treatment of adult ADHD patients with current substance abuse, both on core ADHD symptoms and the substance abuse.

When evaluating efficacy of medication on outcome measures for other symptoms than core ADHD symptoms, ie, anxiety, depression and quality of life, we could not find evidence for a positive effect. Actually there are indications for a negative impact on outcome measures of anxiety and depression (Tenenbaum et al 2002; Michelson et al 2003; Kooij et al 2004). One explanation for this result may be that many studies have low baseline measures on rating scales like Hamilton anxiety and depression scales (HAM-A/D) and Beck depression and anxiety inventories (BDI/BAI), in accordance with the low current comorbidity levels in the samples. Another possibility is that many patients really do not experience a relief in symptoms of anxiety and depression from their ADHD medication, and that this lack of relief, or even worsening of symptoms, may have a negative impact on treatment adherence in the long run.

The placebo responses observed in newer studies are considerably higher than in earlier studies. The reasons for these increasing rates of placebo responses are unclear. A cohort effect because the disorder has been increasingly recognized and treated, or differences in titration of dose (forced versus flexibly), have been suggested as possible explanations (Biederman et al 2006). However, this finding is consistent with a large review of 75 placebo-controlled trials of antidepressants as treatment for major depression (Walsh et al 2002), showing a growing placebo response in studies over decades, and that in half of the studies the placebo response exceeded $30 \%$. Only year of publication was a significant predictor of placebo response.

There are still very few controlled studies of psychotherapy in adult ADHD, but the three studies presented here were adequately performed and with promising results showing response rates and effect sizes comparable to the pharmacologic studies. One study had a long follow-up period, showing persisting good results on core ADHD symptoms up to one year. Two relevant open studies on psychotherapy in adult ADHD (Hesslinger et al 2002; Rostain and Ramsay 2006) support the findings in the randomized controlled studies indicating efficacy of cognitive therapy in adult ADHD. 
The present study indicate that clinicians still have good support for treating adult ADHD patients with stimulants and to some extent non-stimulants, but both clinicians and patients should not be dazzled by the initial good response that may come. It is important to follow the patients over a long time and to take measures to prevent discontinuation of treatment. An individualized titration seems warranted. However, the clinician should know that for many patients with adult ADHD medication may not have a major impact on their problems and symptoms. This is especially the fact for patients with current comorbid substance abuse. There is growing evidence for the efficacy of cognitive behavioral psychotherapy both for medicated and non-medicated patients, and clinicians should make an effort to offer their patients this type of treatment.

Further controlled research assessing efficacy and effectiveness of pharmacological and psychotherapeutic treatments in long-term studies should attend to the impact of treatment on other measures than core ADHD symptoms, like comorbid disorders, quality of life and functional impairment. The impact of comorbid disorders and specific ADHD subgroups as predictors for treatment outcome should also be focused.

\section{References}

Aanonsen NO, Lensing MB, Prietz R, et al. 2004. Utproevende behandling med sentralstimulerende legemidler til voksne med hyperkinetisk forstyrrelse/ADHD. Oslo: Ullevaal University Hospital.

Adler LA, Reingold LS, Morrill MS, et al. 2006. Combination pharmacotherapy for adult ADHD. Curr Psychiatry Rep, 8:409-15.

Adler LA, Spencer TJ, Milton DR, et al. 2005. Long-term, open-label study of the safety and efficacy of atomoxetine in adults with attentiondeficit/hyperactivity disorder: an interim analysis. J Clin Psychiatry, 66:294-9.

American Psychiatric Association. 1994. Diagnostic and Statistical Manual of Mental Disorders, 4th edition (DSM-IV). Washington: American Psychiatric Association.

Asherson P, Chen W, Craddock B, et al. 2007. Adult attention-deficit hyperactivity disorder: recognition and treatment in general adult psychiatry. Br J Psychiatry, 190:4-5.

Barkley RA, Murphy KR, O'Connell T, et al. 2005. Effects of two doses of methylphenidate on simulator driving performance in adults with attention deficit hyperactivity disorder. $J$ Safety Res, 36:121-31.

Biederman J, Mick E, Surman C, et al. 2006. A randomized, placebocontrolled trial of OROS methylphenidate in adults with attentiondeficit/hyperactivity disorder. Biol Psychiatry, 59:829-35.

Biederman J, Spencer TJ, Wilens TE, et al. 2005. Long-term safety and effectiveness of mixed amphetamine salts extended release in adults with ADHD. CNS Spectr, 10:16-25.

Bouffard R, Hechtman L, Minde K, et al. 2003. The efficacy of 2 different dosages of methylphenidate in treating adults with attention-deficit hyperactivity disorder. Can J Psychiatry, 48:546-54.

Capone N, McDonnel T. 2006. Medication persistence among agents used to treat attention-deficit/hyperactivity disorder, diabetes, and elevated serum cholesterol. In American Psychiatric Association 2006 Annual meeting. Toronto: American Psychiatric Association.

Carpentier PJ, de Jong CA, Dijkstra BA, et al. 2005. A controlled trial of methylphenidate in adults with attention deficit/hyperactivity disorder and substance use disorders. Addiction, 100:1868-74.
Clarke S, Heussler H, Kohn MR. 2005. Attention deficit disorder: not just for children. Intern Med J, 35:721-5.

Dodson WW. 2005. Pharmacotherapy of adult ADHD. J Clin Psychol, 61:589-606.

Faraone SV, Biederman J, Mick E. 2006. The age-dependent decline of attention deficit hyperactivity disorder: a meta-analysis of follow-up studies. Psychol Med, 36:159-65.

Faraone SV, Spencer T, Aleardi M, et al. 2004. Meta-analysis of the efficacy of methylphenidate for treating adult attention-deficit/hyperactivity disorder. J Clin Psychopharmacol, 24:24-9.

Foreman DM, Foreman D, Prendergast M, et al. 2001. Is clinic prevalence of ICD-10 hyperkinesis underestimated? Impact of increasing awareness by a questionnaire screen in an UK clinic. Eur Child Adolesc Psychiatry, 10:130-4.

Gordon M, Antshel K, Faraone S, et al. 2006. Symptoms versus impairment: the case for respecting DSM-IV's Criterion D. J Atten Disor, 9:465-75.

Gualtieri CT, Ondrusek MG, Finley C. 1985. Attention deficit disorders in adults. Clin Neuropharmacol, 8:343-56.

Hesslinger B, van Tebartz EL, Nyberg E, et al. 2002. Psychotherapy of attention deficit hyperactivity disorder in adults - a pilot study using a structured skills training program. Eur Arch Psychiatry Clin Neurosci, 252:177-84

Jensen PS, Martin D, Cantwell DP. 1997. Comorbidity in ADHD: implications for research, practice, and DSM-V. J Am Acad Child Adolesc Psychiatry, 36:1065-79.

Kooij JJ, Buitelaar JK, van den Oord EJ, et al. 2005. Internal and external validity of attention-deficit hyperactivity disorder in a population-based sample of adults. Psychol Med, 35:817-27.

Kooij JJ, Burger H, Boonstra AM, et al. 2004. Efficacy and safety of methylphenidate in 45 adults with attention-deficit/hyperactivity disorder. A randomized placebo-controlled double-blind cross-over trial. Psychol Med, 34:973-82.

Kuperman S, Perry PJ, Gaffney GR, et al. 2001. Bupropion SR vs methylphenidate vs placebo for attention deficit hyperactivity disorder in adults. Ann Clin Psychiatry, 13:129-34.

Levin ED, Conners CK, Silva D, et al. 2001. Effects of chronic nicotine and methylphenidate in adults with attention deficit/hyperactivity disorder. Exp Clin Psychopharmacol, 9:83-90.

Levin FR, Evans SM, Brooks DJ, et al. 2007. Treatment of cocaine dependent treatment seekers with adult ADHD: Double-blind comparison of methylphenidate and placebo. Drug Alcohol Depend, 87:20-9.

Levin FR, Evans SM, Brooks DJ, et al. 2006. Treatment of methadonemaintained patients with adult ADHD: double-blind comparison of methylphenidate, bupropion and placebo. Drug Alcohol Depend, $81: 137-48$.

Mattes JA, Boswell L, Oliver H. 1984. Methylphenidate effects on symptoms of attention deficit disorder in adults. Arch Gen Psychiatry, 41:1059-1063.

Michelson D, Adler L, Spencer T, et al. 2003. Atomoxetine in adults with ADHD: two randomized, placebo-controlled studies. Biol Psychiatry, 53:112-20.

MTA Cooperative Group. 2004. National Institute of Mental Health Multimodal Treatment Study of ADHD follow-up: 24-month outcomes of treatment strategies for attention-deficit/hyperactivity disorder. Pediatrics, 113:754-61.

Murphy K, Barkley RA. 1996. Attention deficit hyperactivity disorder adults: comorbidities and adaptive impairments. Compr Psychiatry, 37:393-401.

Nutt DJ, Fone K, Asherson P, et al. 2007. Evidence-based guidelines for management of attention-deficit/hyperactivity disorder in adolescents in transition to adult services and in adults: recommendations from the British Association for Psychopharmacology. J Psychopharmacol, 21:10-41.

Paterson R, Douglas C, Hallmayer J, et al. 1999. A randomised, double-blind, placebo-controlled trial of dexamphetamine in adults with attention deficit hyperactivity disorder. Aust N Z J Psychiatry, 33:494-502. 
Perwien A, Hall J, Swensen A, et al. 2004. Stimulant treatment patterns and compliance in children and adults with newly treated attention-deficit/ hyperactivity disorder. J Manag Care Pharm, 10:122-9.

Rasmussen K, Almvik R, Levander S. 2001. Attention deficit hyperactivity disorder, reading disability, and personality disorders in a prison population. J Am Acad Psychiatry Law, 29:186-93.

Reimherr FW, Williams ED, Strong RE, et al. 2007. A double-blind, placebo-controlled, crossover study of osmotic release oral system methylphenidate in adults with ADHD with assessment of oppositional and emotional dimensions of the disorder. J Clin Psychiatry, 68:93-101.

Rostain AL, Ramsay JR. 2006. A combined treatment approach for adults with ADHD--results of an open study of 43 patients. J Atten Disord, 10:150-9.

Safren SA, Otto MW, Sprich S, et al. 2005. Cognitive-behavioral therapy for ADHD in medication-treated adults with continued symptoms. Behav Res Ther, 43:831-42.

Schachter HM, Pham B, King J, et al. 2001. How efficacious and safe is short-acting methylphenidate for the treatment of attentiondeficit disorder in children and adolescents? A meta-analysis. CMAJ, 165:1475-88

Schubiner H, Saules KK, Arfken CL, et al. 2002. Double-blind placebo-controlled trial of methylphenidate in the treatment of adult ADHD patients with comorbid cocaine dependence. Exp Clin Psychopharmacol, 10:286-94.

Smith BH, Waschbusch DA, Willoughby MT, et al. 2000. The efficacy, safety, and practicality of treatments for adolescents with attentiondeficit/hyperactivity disorder (ADHD). Clin Child Fam Psychol Rev, 3:243-67.

Spencer T, Biederman J, Wilens T, et al. 2005. A large, double-blind, randomized clinical trial of methylphenidate in the treatment of adults with attention-deficit/hyperactivity disorder. Biol Psychiatry, 57:456-63.

Spencer T, Biederman J, Wilens T, et al. 2001. Efficacy of a mixed amphetamine salts compound in adults with attention-deficit/ hyperactivity disorder. Arch Gen Psychiatry, 58:775-82.

Spencer T, Biederman J, Wilens T, et al. 1998. Effectiveness and tolerability of tomoxetine in adults with attention deficit hyperactivity disorder. $\mathrm{Am}$ J Psychiatry, 155:693-5.

Spencer T, Wilens T, Biederman J, et al. 1995. A double-blind, crossover comparison of methylphenidate and placebo in adults with childhoodonset attention-deficit hyperactivity disorder. Arch Gen Psychiatry, 52:434-43.

Spencer TJ, Adler LA, McGough JJ, et al. 2007. Efficacy and safety of dexmethylphenidate extended-release capsules in adults with attentiondeficit/hyperactivity disorder. Biol Psychiatry, 15:1380-7.

Stevenson CS, Stevenson RJ, Whitmont S. 2003. A self-directed psychosocial intervention with minimal therapist contact for adults with attention deficit hyperactivity disorder. Clin Psychol Psychother, 10:93-101.

Stevenson CS, Whitmont S, Bornholt L, et al. 2002. A cognitive remediation programme for adults with Attention Deficit Hyperactivity Disorder. Aust N J Psychiatry, 36:610-6.
Taylor, FB, Russo J. 2000. Efficacy of modafinil compared to dextroamphetamine for the treatment of attention deficit hyperactivity disorder in adults. J Child Adolesc Psychopharmacol, 10:311-20.

Taylor FB, Russo J. 2001. Comparing guanfacine and dextroamphetamine for the treatment of adult attention-deficit/hyperactivity disorder. J Clin Psychopharmacol, 21:223-8.

Tenenbaum S, Paull JC, Sparrow EP, et al. 2002. An experimental comparison of Pycnogenol and methylphenidate in adults with Attention-Deficit/Hyperactivity Disorder (ADHD). J Atten Disord, 6:49-60.

Torgersen T, Gjervan B, Rasmussen K. 2006. ADHD in adults: a study of clinical characteristics, impairment and comorbidity. Nord J Psychiatry, 60:38-43.

Tripp G, Luk SL, Schaughency EA, et al. 1999. DSM-IV and ICD-10: a comparison of the correlates of ADHD and hyperkinetic disorder. $J \mathrm{Am}$ Acad Child Adolesc Psychiatry, 38:156-64.

Walsh BT, Seidman SN, Sysko R, et al. 2002. Placebo response in studies of major depression: variable, substantial, and growing. JAMA, 287:1840-7.

Weisler RH, Biederman J, Spencer TJ, et al. 2006. Mixed amphetamine salts extended-release in the treatment of adult ADHD: a randomized, controlled trialCNS Spectr, 11:625-39.

Weiss M, Hechtman L. 2006. A randomized double-blind trial of paroxetine and/or dextroamphetamine and problem-focused therapy for attentiondeficit/hyperactivity disorder in adults. J Clin Psychiatry, 67:611-9.

Weiss MD, Gadow K, Wasdell MB. 2006. Effectiveness outcomes in attention-deficit/hyperactivity disorder. J Clin Psychiatry, 67:38-45.

Wender PH. 1998. Pharmacotherapy of attention-deficit/hyperactivity disorder in adults. J Clin Psychiatry, 59:76-9.

Wender PH, Reimherr FW, Wood D, et al. 1985. A controlled study of methylphenidate in the treatment of attention deficit disorder, residual type, in adults. Am J Psychiatry, 142:547-52.

Wilens TE, Biederman J, Prince J, et al. 1996. Six-week, double-blind, placebo-controlled study of desipramine for adult attention deficit hyperactivity disorder. Am J Psychiatry, 153:1147-53.

Wilens TE, Biederman J, Spencer TJ. 2002. Attention deficit/hyperactivity disorder across the lifespan. Annu Rev Med, 53:113-31.

Wilens TE, Haight BR, Horrigan JP, et al. 2005. Bupropion XL in adults with attention-deficit/hyperactivity disorder: a randomized, placebocontrolled study. Biol Psychiatry, 57:793-801.

Wilens TE, Spencer TJ, Biederman J. 2002. A review of the pharmacotherapy of adults with attention-deficit/hyperactivity disorder. J Atten Disord, 5:189-202.

Wilens TE, Spencer TJ, Biederman J, et al. 2001. A controlled clinical trial of bupropion for attention deficit hyperactivity disorder in adults. Am J Psychiatry, 158:282-88.

Wood DR, Reimherr FW, Wender PH, et al. 1976. Diagnosis and treatment of minimal brain dysfunction in adults: a preliminary report. Arch Gen Psychiatry, 33:1453-60.

World Health Organization. 1992. The International Classification of Disease, 10th revision. Geneva: World Health Organization. 